\title{
Birth weight modifies the association between central nervous system gene variation and adult body mass index
}

\author{
Edward A Ruiz-Narváez ${ }^{1,2}$, Stephen A Haddad ${ }^{1,2}$, Lynn Rosenberg ${ }^{1,2}$ and Julie R Palmer ${ }^{1,2}$
}

Genome wide association studies have identified $\sim 100$ loci associated with body mass index (BMI). Persons with low birth weight have an increased risk of metabolic disorders. We postulate that normal mechanisms of body weight regulation are disrupted in subjects with low birth weight. The present analyses included 2215 African American women from the Black Women's Health Study, and were based on genotype data on $20 \mathrm{BMI}$-associated loci and self-reported data on birth weight, weight at age 18 and adult weight. We used general linear models to assess the association of individual single-nucleotide polymorphisms (SNPs) with BMI at age 18 and later in adulthood within strata of birth weight (above and below the median, $3200 \mathrm{~g}$ ). Three SNPs (rs1320330 near TMEM18, rs261967 near PCSK1 and rs17817964 in FTO), and a genetic score combining these three variants, showed significant interactions with birth weight in relation to BMI. Among women with birth weight $<3200 \mathrm{~g}$, there was an inverse association between genetic score and $\mathrm{BMI}$; beta-coefficient $=-0.045(95 \%$ confidence intervals $(\mathrm{Cl})-0.104,0.013)$ for $\mathrm{BMI}$ at age 18 , and $-0.055(95 \% \mathrm{Cl}-0.112,0.002)$ for adult $\mathrm{BMI}$. Among women with birth weight $\geqslant 3200 \mathrm{~g}$, genetic score was positively associated with BMI: beta-coefficient $=0.110(95 \% \mathrm{Cl} 0.051,0.169)$ for $\mathrm{BMI}$ at age $18(P$ for interaction $=0.0002)$, and $0.112(95 \% \mathrm{Cl} 0.054,0.170)$ for adult $\mathrm{BMI}(P$ for interaction $<0.0001)$. Because TMEM18, PCSK1 and FTO are highly expressed in the central nervous system (CNS), our results suggest that low-birth weight may disrupt mechanisms of CNS body weight regulation.

Journal of Human Genetics (2016) 61, 193-198; doi:10.1038/jhg.2015.139; published online 19 November 2015

\section{INTRODUCTION}

Low birth weight, a marker of compromised fetal growth, has consistently been found to be associated with higher risk of type 2 diabetes (T2D) in adulthood. ${ }^{1,2}$ Although it was initially postulated that the association between low birth weight and metabolic disorders in adulthood was in part due to a higher risk of obesity, ${ }^{3-5}$ recent large-scale meta-analyses have reported that persons who had a low birth weight have in fact a lower adult body mass index (BMI) and a decreased risk of being overweight or obese later in life, compared with subjects with normal birth weight. ${ }^{6-8}$ Findings from our study of participants in the Black Women's Health Study (BWHS) indicate that the association between low birth weight and adult risk of T2D is not mediated through BMI. ${ }^{9}$ Growing evidence suggests that alterations of the neuroendocrine system, ${ }^{10-13}$ deregulation of lipid metabolism ${ }^{14-16}$ and pancreatic dysfunction ${ }^{17-19}$ rather than increased risk of obesity may have a key mediating role between low birth weight and risk of T2D and other metabolic disorders in adulthood.

Genome wide association studies (GWAS) — in mostly European ancestry populations - have identified $\sim 100$ genetic loci belonging to multiple pathways, such as central nervous system (CNS) function, insulin secretion and action, energy metabolism and lipid biology and adipogenesis associated with variation in BMI and body weight. ${ }^{20-25}$ In
African ancestry populations only eight of these loci show genomewide significant association $\left(P \leqslant 5 \times 10^{-8}\right)$ with $\mathrm{BMI}$, and twenty loci have significant association at the gene-wide level $(P \leqslant 0.001) .{ }^{21} \mathrm{We}$ postulate that because of the multiple alterations associated with low birth weight, normal genetic mechanisms of body weight regulation are not completely functional in persons who had a low birth weight. Thus, the association between BMI-associated gene variants and body weight would be modified among individuals with low birth weight. In particular, because pathway analysis shows a key role of the CNS in body weight regulation, ${ }^{25}$ we hypothesize that CNS gene variants are more likely to interact with birth weight in relation to adult BMI.

We tested this hypothesis in the BWHS, a prospective cohort study of 59000 African American women.

\section{MATERIALS AND METHODS}

Study subjects

The present analyses were carried out in data from the BWHS. The BWHS began in 1995 when 59000 African American women 21-69 years of age from across the continental US completed a 14-page postal questionnaire that included comprehensive questions on anthropometric measures, medical history, use of medications, demographic factors, reproductive history and behavioral factors. ${ }^{26}$ Participants were approximately equally distributed in the

\footnotetext{
${ }^{1}$ Slone Epidemiology Center at Boston University, Boston, MA, USA and ${ }^{2}$ Department of Epidemiology, Boston University School of Public Health, Boston, MA, USA Correspondence: Dr EA Ruiz-Narváez, Slone Epidemiology Center at Boston University, 1010 Commonwealth Avenue, 4th floor, Boston, 02215 MA, USA. E-mail: eruiznar@bu.edu

Received 1 July 2015; revised 23 October 2015; accepted 26 October 2015; published online 19 November 2015
} 
Northeast, South, Midwest and West. Participants have been followed through biennial questionnaires to collect information on incident diseases and update information on risk factors. Follow-up through biennial questionnaires has been $\sim 80 \%$ of the baseline cohort. DNA samples were obtained from BWHS participants by the mouthwash-swish method ${ }^{27}$ with all samples stored in freezers at $-80^{\circ} \mathrm{C}$. Saliva samples were provided by $\sim 50 \%$ of BWHS participants (26800 women). The study protocol was approved by the Institutional Review Board of Boston University. Written informed consent was obtained from all subjects.

Subjects for the present analysis were BWHS participants who had previously been selected as controls for a nested case control study of genes and environment in relation to T2D and obesity risk. They were participants who had not been diagnosed with T2D, had provided a DNA sample and completed questions on birth weight on the 1997 questionnaire. The final analytic sample size included 2215 subjects with information on birth weight and complete genotyping of 20 BMI-associated single-nucleotide polymorphisms (SNPs). This sample size allows us $80 \%$ power to identify an effect of 0.03 or higher of the genetic variants on BMI transformed residuals. This effect is within the range of genetic effects found in a recent GWAS meta-analysis of BMI in African ancestry subjects. ${ }^{21}$

\section{Selection of SNPs and genotyping}

We selected the 20 SNPs that were found to be associated with BMI at the genewide level $(P \leqslant 0.001$, including SNPs associated at the genome-wide level) in a recent GWAS meta-analysis in African ancestry subjects. ${ }^{21}$

DNA samples were genotyped on an Affymetrix Axiom 45-K custom array (Affymetrix, Santa Clara, CA, USA) designed to include genes and SNPs related to $\mathrm{BMI}$ and $\mathrm{T} 2 \mathrm{D}$, or related to relevant pathways such as adiponectin and leptin levels, fasting insulin and glucose, insulin resistance and fatty acid metabolism. In addition, the array included $\sim 3 \mathrm{~K}$ ancestral informative markers to estimate percentage of European ancestry. Genotyping was carried out at the Affymetrix laboratory, Santa Clara, CA. The genotype data passed Affymetrix quality control standards. Final mean calling rate for SNPs and subjects was $99.5 \%$, mean reproducibility among blinded duplicates was $99.7 \%$ and mean concordance with HapMap samples was $99.5 \%$.

\section{Assessment of BMI}

Information on weight at age 18, current weight, and current height, obtained from the baseline questionnaire (1995), were used to calculate BMI $\left(\mathrm{kg} \mathrm{m}^{-2}\right)$ at age 18 and adulthood. In a validation study of anthropometric measures conducted among 115 BWHS participants, Spearman correlations for selfreported versus technician measured weight and height were 0.97 and 0.93 respectively. ${ }^{28}$

\section{Birth weight assessment}

On the 1997 follow-up questionnaire, women were asked their birth weight in categories ( $<4 \mathrm{lb}, 4-5 \mathrm{lb} 8 \mathrm{oz},>5 \mathrm{lb} 8 \mathrm{oz}$, do not know) and their exact birth weight in pounds and ounces, if known. We used information from both questions to create categories of birth weight (bottom $50 \%$ vs top $50 \%$; and low birth weight $<2500 \mathrm{~g}$ vs normal birth weight $\geqslant 2500 \mathrm{~g}$ ). We carried out a validation study among 637 BWHS participants born in Massachusetts using birth registry data from the Massachusetts Department of Public Health to corroborate self-reported data on birth weight. The kappa-coefficient of agreement was 0.80 for the categorical data, and the correlation was 0.88 for exact self-reported birth weight. ${ }^{9}$

\section{Covariates}

Data on vigorous physical activity (hours per week), smoking, and years of education were obtained from the 1995 questionnaire. Information on energy intake (kilocalories per day) was estimated from a 1995 food frequency questionnaire $^{29}$ using the DIET ${ }^{\star}$ CALC software version 1.4.1 (National Cancer Institute, Bethesda, MD, USA). ${ }^{30}$

\section{Data analysis}

BMI was regressed on age and age squared to obtain residuals. Residuals were inverse normally transformed to obtain a standardized normal distribution with mean of 0 and s.d. of $1 .{ }^{21}$ We used linear regression models to estimate betacoefficients and 95\% confidence intervals (CI) of the association between genetic variants and BMI-transformed residuals. Models were adjusted for vigorous physical activity (none, $<1 \mathrm{~h}$ per week, $1-4 \mathrm{~h}$ per weeks and $\geqslant 5 \mathrm{~h}$ per week), smoking (never, past and current), years of education $(\leqslant 12,13-15,16$, $\geqslant 17$ years), dietary energy intake (kilocalories per day) and percentage of European ancestry. We used a Bayesian approach, as implemented in the Admixmap software (University of Edinburgh, Edinburgh, UK) ${ }^{31,32}$ to estimate individual proportions of European ancestry using genotypes of 3077 ancestral informative markers included in the Affymetrix Axiom array.

We tested the hypothesis that the association of genetic variants with BMI is modified among persons with low birth weight by conducting the regression analyses within strata of birth weight (bottom 50\% and top 50\%). We used cross-product interaction terms for SNP and binary birth weight in the regression models. Statistical significance of the cross product term was assessed by the likelihood ratio test comparing models with and without interaction terms. We then calculated a genetic risk score using the SNPs with a nominal significant interaction $(P \leqslant 0.05)$ with birth weight in relation to BMI. The score is the sum of BMI increasing alleles. Association of the genetic score with BMI and interaction with birth weight was assessed using general linear models as described for the individual SNPs. All analyses were performed using SAS version 9.4 (SAS Institute, Cary, NC, USA).

\section{RESULTS}

Table 1 shows characteristics of the study participants by birth weight categories (bottom 50\%: <3200 g, top 50\%: $\geqslant 3200 \mathrm{~g}$ ). Subjects with birth weight in the top $50 \%$ had higher BMI both at age 18 and adulthood compared with subjects in the bottom $50 \%$ of birth weight.

\section{Table 1 Baseline (1995) characteristics of BWHS participants, by birth weight}

\begin{tabular}{|c|c|c|}
\hline \multirow[b]{2}{*}{ Characteristic } & \multicolumn{2}{|c|}{ Birth weight } \\
\hline & $<3200 g$ & $\geqslant 3200 \mathrm{~g}$ \\
\hline Number of women & 1113 & 1102 \\
\hline Gene score (mean) & 2.8 & 2.8 \\
\hline European ancestry, \% (mean) & 22.0 & 22.6 \\
\hline Age, $y$ (mean) & 39.9 & 40.3 \\
\hline $\mathrm{BMI}$ at age $18, \mathrm{~kg} \mathrm{~m}^{-2}$ (mean) & 20.9 & 21.5 \\
\hline BMI, $\mathrm{kg} \mathrm{m}^{-2}$ (mean) & 27.1 & 27.9 \\
\hline Energy intake (1995), kcal per day (mean) & 1482 & 1469 \\
\hline \multicolumn{3}{|l|}{ Smoking, \% } \\
\hline Never & 63 & 64 \\
\hline Past & 21 & 21 \\
\hline Current & 16 & 15 \\
\hline \multicolumn{3}{|l|}{ Vigorous exercise, \% } \\
\hline None & 31 & 31 \\
\hline$<1 \mathrm{~h}$ per week & 18 & 18 \\
\hline 1-4 h per week & 40 & 38 \\
\hline$\geqslant 5 \mathrm{~h}$ perweek & 12 & 13 \\
\hline \multicolumn{3}{|l|}{ Education } \\
\hline$\leqslant 12$ years & 13 & 14 \\
\hline $13-15$ years & 36 & 35 \\
\hline 16 years & 26 & 23 \\
\hline$\geqslant 17$ years & 24 & 28 \\
\hline
\end{tabular}

Abbreviations: BMI, body mass index; BWHS, Black Women's Health Study. 
Table 2 List of selected SNPs

Beta $(95 \%$ CI) in BWHS

\begin{tabular}{|c|c|c|c|c|c|c|c|}
\hline SNP & Gene & Alleles $^{\mathrm{a}}$ & $E A \digamma^{b}$ & GWAS Beta & $B M I$ at age 18 & Adult BMI & $P-H W E^{\mathrm{d}}$ \\
\hline rs12562499e & PTBP2 & $C / G$ & 0.09 & 0.048 & $0.067(-0.033,0.167)$ & $0.049(-0.049,0.146)$ & 0.53 \\
\hline rs543874 & SEC16B & $\mathrm{G} / \mathrm{A}$ & 0.24 & 0.060 & $0.119(0.056,0.183)^{* * *}$ & $0.109(0.046,0.171)^{* * *}$ & 0.79 \\
\hline rs1320330 & TMEM18 & $\mathrm{G} / \mathrm{T}$ & 0.88 & 0.061 & $0.118(0.033,0.202)^{* *}$ & $0.034(-0.049,0.116)$ & 0.92 \\
\hline rs7586879 & POMC & $\mathrm{T} / \mathrm{C}$ & 0.76 & 0.042 & $0.054(-0.012,0.120)$ & $0.043(-0.022,0.107)$ & 0.91 \\
\hline rs9816226e & ATV5 & $\mathrm{T} / \mathrm{A}$ & 0.80 & 0.042 & $0.122(0.052,0.192)^{* * *}$ & $0.105(0.036,0.173)^{* *}$ & 0.02 \\
\hline rs10938397e & GNPDA2 & $\mathrm{G} / \mathrm{A}$ & 0.23 & 0.053 & $-0.003(-0.068,0.063)$ & $0.003(-0.061,0.067)$ & 0.38 \\
\hline rs7708584 & GALNT1O & $A / G$ & 0.31 & 0.040 & $0.060(0.001,0.119)^{*}$ & $0.072(0.015,0.130)^{*}$ & 0.68 \\
\hline rs261967 & PCSK1 & $\mathrm{C} / \mathrm{A}$ & 0.39 & 0.026 & $-0.011(-0.066,0.044)$ & $0.004(-0.050,0.058)$ & 0.77 \\
\hline rs974417 & KLHL32 & $\mathrm{C} / \mathrm{T}$ & 0.65 & 0.031 & $0.015(-0.043,0.073)$ & $-0.049(-0.105,0.008)$ & 0.24 \\
\hline rs987237 & TFAP2B & $\mathrm{G} / \mathrm{A}$ & 0.11 & 0.051 & $0.086(-0.001,0.173)$ & $0.081(-0.004,0.166)$ & 0.30 \\
\hline rs10968576 & LRRN6C & $\mathrm{G} / \mathrm{A}$ & 0.17 & 0.037 & $0.093(0.021,0.164)^{*}$ & $0.083(0.014,0.153)^{*}$ & 0.21 \\
\hline rs10501087 & $B D N F$ & $\mathrm{~T} / \mathrm{C}$ & 0.93 & 0.081 & $-0.009(-0.117,0.099)$ & $0.070(-0.036,0.175)$ & 0.29 \\
\hline rs7138803 & FAIM2 & $A / G$ & 0.18 & 0.047 & $0.020(-0.045,0.094)$ & $0.055(-0.013,0.124)$ & 0.56 \\
\hline rs10150332e & $N R X N 3$ & $\mathrm{C} / \mathrm{T}$ & 0.34 & 0.034 & $0.021(-0.037,0.078)$ & $0.001(-0.056,0.057)$ & 0.38 \\
\hline rs2241423 & MAP2K5 & $\mathrm{G} / \mathrm{A}$ & 0.63 & 0.028 & $0.058(0.001,0.114)^{*}$ & $0.087(0.032,0.142)^{* *}$ & 0.93 \\
\hline rs7359397 & $S H 2 B 1$ & $\mathrm{~T} / \mathrm{C}$ & 0.08 & 0.053 & $0.083(-0.020,0.185)$ & $0.064(-0.037,0.164)$ & 0.37 \\
\hline rs17817964 & FTO & $\mathrm{T} / \mathrm{C}$ & 0.12 & 0.073 & $0.027(-0.058,0.113)$ & $0.074(-0.010,0.157)$ & 0.85 \\
\hline rs12597579 & GP2 & $\mathrm{C} / \mathrm{T}$ & 0.90 & 0.037 & $-0.001(-0.094,0.091)$ & $0.067(-0.023,0.158)$ & 0.65 \\
\hline rs6567160e & $M C 4 R$ & $\mathrm{C} / \mathrm{T}$ & 0.22 & 0.059 & $0.044(-0.022,0.110)$ & $0.064(-0.001,0.129)$ & 0.95 \\
\hline rs2287019e & QPCTL & $\mathrm{C} / \mathrm{T}$ & 0.91 & 0.066 & $0.052(-0.042,0.146)$ & $0.033(-0.059,0.126)$ & 0.63 \\
\hline
\end{tabular}

Abbreviations: BMI, body mass index; BWHS, Black Women's Health Study; EAF, effect allele frequency; GWAS, Genome wide association studies; P-HWE, P value for test of Hardy-Weinberg proportions; SNP, single-nucleotide polymorphisms.

${ }^{a}$ Effect allele/reference allele.

bEffect allele frequency in the BWHS.

${ }^{c}$ Change in BMI residuals for each copy of the effect allele. Adjusted for age, \% European ancestry, dietary energy intake, smoking, vigorous exercise and education. Betas for BMI at age 18 were adjusted for \% European ancestry only.

d $P$ for test of Hardy-Weinberg proportions.

eProxies: rs12562499, rs10783050; rs9816226, rs73052046; rs10938397, rs10938398; rs10150332, rs10146997; rs6567160, rs1539952; rs2287019, rs12976464

${ }^{*} P \leqslant 0.05,{ }^{* *} P \leqslant 0.01,{ }^{* * *} P \leqslant 0.001$.

The birth weight groups were similar with respect to the other characteristics-age, \% European ancestry, energy intake, smoking, vigorous exercise and education.

Table 2 shows the list of 20 selected SNPs and their association with BMI at age 18, and adult BMI in the BWHS. Most of the SNPs (16 for BMI at age 18, and 19 for adult BMI) showed directionally consistent effects compared with previous GWAS results. The magnitude of the effects was also consistent for most of the examined variants.

Table 3 shows SNP-BMI association results stratified by birth weight (bottom 50\%: $<3200 \mathrm{~g}$, top 50\%: $\geqslant 3200 \mathrm{~g}$ ). Two SNPs, rs1320330 near TMEM18 and rs261967 near PCSK1, showed significant interactions with birth weight in relation to both BMI at age 18 and adult BMI; and one SNP, rs17817964 in FTO, had a significant interaction with birth weight in relation to adult BMI only. For these three SNPs, the effect allele was associated with higher BMI among women with birth weight $\geqslant 3200 \mathrm{~g}$, and either a weaker positive association or an inverse association with BMI among women with birth weight $<3200$ g. For example, the beta $(95 \% \mathrm{CI})$ for the $\mathrm{G}$ allele in rs1320330 was $0.205(0.085,0.325)$ among women with birth weight $\geqslant 3200 \mathrm{~g}$ and $0.032(-0.087,0.150)$ among women with birth weight $<3200 \mathrm{~g}$ for BMI at age 18 ( $P$ for interaction $=0.04$ ); for adult $\mathrm{BMI}$, it was $0.146(0.029,0.263)$ among women with birth weight $\geqslant 3200 \mathrm{~g}$ and $-0.077(-0.193,0.039)$ among women with birth weight $<3200 \mathrm{~g}$ ( $P$ for interaction $=0.008)$.

Table 4 shows the association of genetic score with BMI stratified by birth weight. The genetic score is the sum of BMI-increasing alleles of the three SNPs (rs1320330, rs261967 and rs17817964) found to have significant interactions with birth weight. The mean of the genetic score in the study sample was 2.8 alleles, with ranged 0-6 alleles. Genetic score was positively associated with BMI both at age 18 and adulthood in multivariate models adjusted for age, European ancestry, dietary energy intake, smoking, vigorous physical activity and education. The increase in BMI residuals per allele was 0.031 (95\% CI $-0.011,0.073)$ for BMI at age 18 and 0.027 (95\% CI $-0.014,0.068)$ for BMI at adulthood. The genetic score was positively associated with BMI at age 18 among individuals with birth weight in the top 50\% $(\geqslant 3200 \mathrm{~g})$, beta $=0.110$ (95\% CI $0.051,0.169)$; and tended to have a negative association with BMI among individuals with birth weight in the bottom 50\% (<3200 g), beta $=-0.045$ (95\% CI $-0.105,0.013 ; P$ for interaction $=0.0002)$. Similar results were observed for adult BMI; a positive association with BMI among women with birth weight $\geqslant 3200 \mathrm{~g}$, beta $=0.112 \quad(95 \%$ CI $0.054,0.170)$, and a negative association with BMI among women with birth weight $<3200 \mathrm{~g}$, beta $=-0.055$ (95\% CI $-0.112,0.002$; $P$ for interaction $<0.0001)$. In secondary analyses we categorized birth weight as low birth weight $(<2500 \mathrm{~g}, n=349)$, and normal birth weight $(\geqslant 2500 \mathrm{~g}, n=1866)$. There was no association of genetic risk score and BMI among persons with low birth weight for both BMI at age 18 and adulthood. A positive association was present among individuals with normal birth weight, beta $=0.040(95 \% \mathrm{CI}-0.006,0.086)$ for BMI at age 18 ; and $0.038(95 \% \mathrm{CI}-0.007,0.082)$ for adult BMI.

\section{DISCUSSION}

In the present study, we proposed and assessed the hypothesis that the association between variants in BMI-associated genes and body weight is modified by birth weight. In particular, because of the 
neuroendocrine alterations observed in persons with low birth weight ${ }^{10-13}$ and results of pathway analysis showing a key role of CNS gene variants in body weight regulation, ${ }^{25}$ we proposed that CNS genetic mechanisms of body weight regulation would be dysfunctional among individuals with low birth weight. Therefore, the association between BMI-associated CNS-gene variants and adult BMI would be

Table 3 Beta-coefficients for the association of individual SNPs with BMI at age 18 and adulthood in the Black Women's Health Study, overall and by categories of birth weight

\begin{tabular}{|c|c|c|c|c|c|c|c|}
\hline \multirow[b]{3}{*}{ SNP } & \multirow[b]{3}{*}{ Alleles ${ }^{\mathrm{a}}$} & \multicolumn{3}{|c|}{ Beta $(95 \% \mathrm{Cl})^{\mathrm{b}}$ for $\mathrm{BMI}$ at age 18} & \multicolumn{3}{|c|}{ Beta $(95 \% \text { Cl })^{b}$ for Adult BMI } \\
\hline & & \multicolumn{3}{|c|}{ Birth weight } & \multicolumn{3}{|c|}{ Birth weight } \\
\hline & & $<3200 g$ & $\geqslant 3200 \mathrm{~g}$ & $\mathrm{P}^{\mathrm{c}}$ & $<3200 \mathrm{~g}$ & $\geqslant 3200 \mathrm{~g}$ & $\mathrm{P}^{\mathrm{c}}$ \\
\hline rs12562499d & $\mathrm{C} / \mathrm{G}$ & $0.030(-0.110,0.170)$ & $0.103(-0.036,0.243)$ & 0.46 & $-0.016(-0.153,0.120)$ & $0.112(-0.023,0.248)$ & 0.19 \\
\hline rs543874 & $\mathrm{G} / \mathrm{A}$ & $0.076(-0.015,0.167)$ & $0.160(0.072,0.249)$ & 0.19 & $0.099(0.010,0.188)$ & $0.118(0.031,0.205)$ & 0.77 \\
\hline rs1320330 & $\mathrm{G} / \mathrm{T}$ & $0.032(-0.087,0.150)$ & $0.205(0.085,0.325)$ & 0.04 & $-0.077(-0.193,0.039)$ & $0.146(0.029,0.263)$ & 0.008 \\
\hline rs7586879 & $\mathrm{T} / \mathrm{C}$ & $0.064(-0.029,0.156)$ & $0.044(-0.047,0.136)$ & 0.77 & $0.021(-0.070,0.111)$ & $0.064(-0.025,0.154)$ & 0.50 \\
\hline rs9816226d & T/A & $0.139(0.040,0.238)$ & $0.105(0.006,0.205)$ & 0.64 & $0.097(0.000,0.194)$ & $0.112(0.015,0.210)$ & 0.83 \\
\hline rs10938397 & $\mathrm{G} / \mathrm{A}$ & $-0.060(-0.154,0.033)$ & $0.051(-0.039,0.141)$ & 0.09 & $-0.007(-0.098,0.085)$ & $0.012(-0.076,0.101)$ & 0.77 \\
\hline rs7708584 & $A / G$ & $0.044(-0.037,0.126)$ & $0.078(-0.008,0.163)$ & 0.58 & $0.027(-0.053,0.106)$ & $0.123(0.039,0.206)$ & 0.10 \\
\hline rs261967 & $\mathrm{C} / \mathrm{A}$ & $-0.099(-0.178,-0.020)$ & $0.073(-0.004,0.150)$ & 0.002 & $-0.063(-0.141,0.014)$ & $0.069(-0.007,0.144)$ & 0.02 \\
\hline rs974417 & $\mathrm{C} / \mathrm{T}$ & $-0.008(-0.090,0.073)$ & $0.038(-0.044,0.120)$ & 0.43 & $-0.038(-0.118,0.042)$ & $-0.059(-0.139,0.021)$ & 0.71 \\
\hline rs987237 & $\mathrm{G} / \mathrm{A}$ & $0.021(-0.105,0.147)$ & $0.145(0.025,0.266)$ & 0.16 & $0.075(-0.048,0.198)$ & $0.087(-0.031,0.205)$ & 0.89 \\
\hline rs10968576 & $\mathrm{G} / \mathrm{A}$ & $0.114(0.013,0.214)$ & $0.071(-0.031,0.173)$ & 0.56 & $0.106(0.008,0.204)$ & $0.060(-0.040,0.160)$ & 0.52 \\
\hline rs10501087 & $\mathrm{T} / \mathrm{C}$ & $-0.059(-0.208,0.090)$ & $0.045(-0.110,0.199)$ & 0.34 & $0.078(-0.068,0.224)$ & $0.060(-0.091,0.211)$ & 0.86 \\
\hline rs7138803 & $A / G$ & $0.011(-0.088,0.110)$ & $0.037(-0.061,0.136)$ & 0.71 & $0.068(-0.029,0.165)$ & $0.043(-0.053,0.139)$ & 0.72 \\
\hline rs $10150332^{d}$ & $\mathrm{C} / \mathrm{T}$ & $0.040(-0.041,0.122)$ & $0.001(-0.081,0.083)$ & 0.50 & $0.015(-0.065,0.094)$ & $-0.013(-0.093,0.067)$ & 0.63 \\
\hline rs2241423 & $\mathrm{G} / \mathrm{A}$ & $0.051(-0.028,0.131)$ & $0.064(-0.016,0.144)$ & 0.82 & $0.064(-0.014,0.142)$ & $0.110(0.032,0.188)$ & 0.41 \\
\hline rs7359397 & $\mathrm{T} / \mathrm{C}$ & $0.086(-0.055,0.227)$ & $0.079(-0.065,0.224)$ & 0.95 & $0.063(-0.075,0.200)$ & $0.065(-0.077,0.206)$ & 0.98 \\
\hline rs17817964 & $\mathrm{T} / \mathrm{C}$ & $-0.007(-0.126,0.113)$ & $0.062(-0.058,0.182)$ & 0.42 & $-0.020(-0.136,0.097)$ & $0.168(0.051,0.286)$ & 0.03 \\
\hline rs12597579 & $\mathrm{C} / \mathrm{T}$ & $-0.008(-0.135,0.118)$ & $0.007(-0.129,0.143)$ & 0.87 & $0.116(-0.007,0.240)$ & $0.011(-0.122,0.143)$ & 0.25 \\
\hline rs6567160d & $\mathrm{C} / \mathrm{T}$ & $0.051(-0.041,0.144)$ & $0.036(-0.059,0.131)$ & 0.82 & $0.074(-0.016,0.165)$ & $0.054(-0.039,0.146)$ & 0.75 \\
\hline rs2287019d & $\mathrm{C} / \mathrm{T}$ & $0.057(-0.073,0.188)$ & $0.046(-0.091,0.182)$ & 0.90 & $0.038(-0.090,0.166)$ & $0.028(-0.106,0.161)$ & 0.92 \\
\hline
\end{tabular}

Abbreviations: BMI, body mass index; $\mathrm{Cl}$, confidence intervals; SNP, single-nucleotide polymorphisms.

${ }^{a}$ Effect allele/reference allele.

${ }^{b}$ Change in BMI residuals for each copy of the effect allele. Adjusted for age, \% European ancestry, dietary energy intake, smoking, vigorous exercise and education. Betas for BMI at age 18 were adjusted for \% European ancestry only.

c $P$ for interaction.

dProxies: rs12562499, rs10783050; rs9816226, rs73052046; rs10938397, rs10938398; rs10150332, rs10146997; rs6567160, rs1539952; rs2287019, rs12976464.

Table 4 Beta-coefficients for the association of genetic score ${ }^{a}$ with BMI at age 18 and adulthood in the Black Women's Health Study, overall and by categories of birth weight

\begin{tabular}{|c|c|c|}
\hline & \multicolumn{2}{|c|}{ Beta $(95 \% \mathrm{Cl})^{\mathrm{b}}$} \\
\hline & $B M I$ at age 18 & Adult BMI \\
\hline All subjects $(n=2215)$ & $0.031(-0.011,0.073)$ & $0.027(-0.014,0.068)$ \\
\hline \multicolumn{3}{|c|}{ Bottom $50 \%$ vs top $50 \%$ birth weight } \\
\hline$<3200 \mathrm{~g}(n=1113)$ & $-0.045(-0.104,0.013)$ & $-0.055(-0.112,0.002)$ \\
\hline$\geqslant 3200 \mathrm{~g}(n=1102)$ & $0.110(0.051,0.169)$ & $0.112(0.054,0.170)$ \\
\hline$P$ for interaction & 0.0002 & $<0.0001$ \\
\hline \multicolumn{3}{|c|}{ Low birth weight vs normal birth weight } \\
\hline$<2500 \mathrm{~g}(n=349)$ & $-0.015(-0.119,0.090)$ & $-0.029(-0.131,0.073)$ \\
\hline$\geqslant 2500 \mathrm{~g}(n=1866)$ & $0.040(-0.006,0.086)$ & $0.038(-0.007,0.082)$ \\
\hline$P$ for interaction & 0.35 & 0.24 \\
\hline
\end{tabular}

Abbreviations: BMI, body mass index; $\mathrm{Cl}$, confidence intervals.

abenetic score is the sum of BMI-increasing alleles of the SNPs rs1320330 (TMEM18), rs261967 (PCSK1), and rs17817964 (FTO).

${ }^{b}$ Change in BMI residuals for each BMI-increasing allele. Adjusted for age, \% European ancestry, dietary energy intake, smoking, vigorous exercise and education. Betas for BMI at age 18 were adjusted for \% European ancestry only. 
modified in these subjects. We tested 20 SNPs, located in or nearby genes expressed in a variety of tissues, which had previously been found to be associated with BMI in African ancestry subjects. Three of the SNPs (rs1320330 near TMEM18, rs261967 near PCSK1 and rs17817964 in FTO), and a genetic score calculated using these three variants, interacted with birth weight in relation to BMI. All three are located in or near genes that are highly expressed in the CNS.

Available evidence suggests that TMEM18, PCSK1 and FTO regulate body weight in part through their actions in the CNS and adipose tissue. TMEM18, which codes a transmembrane nuclear protein with a wide distribution of tissue expression, ${ }^{33,34}$ is downregulated in the hypothalamus of rats $^{35}$ and adipose tissue of mice ${ }^{36}$ after high-fat feeding. In addition, TMEM18 expression is upregulated during invitro human adipocyte differentiation, ${ }^{34}$ and downregulated in adipose tissue of obese subjects, ${ }^{34}$ suggesting TMEM18 action in adipose tissue too. PCSK1 codes for the neuroendocrine convertase 1 (PC1) that is involved in the processing of several hormones and neuropeptides that regulate feeding behavior and energy metabolism. ${ }^{37,38}$ PCSK1 is mostly expressed in neuroendocrine cells such as in brain and pituitary. ${ }^{39}$ Congenital deficiency of PC1 leads to a severe hormonal dysfunction and early-onset obesity. ${ }^{40,41}$ The FTO gene was one of the first loci found to be associated through GWAS with body weight. ${ }^{22,42}$ The protein coded by FTO is an enzyme with DNA- and RNA-demethylase activity. ${ }^{43,44}$ Although FTO is expressed in a wide variety of tissues, high levels of expression are preferentially observed in the brain, especially in hypothalamus. ${ }^{42,43}$ A growing body of evidence strongly suggest that FTO affects body weight in part through regulation of food intake. ${ }^{45-47}$

If TMEM18, PCSK1 and FTO are indeed regulating body weight in part through their activity in the CNS then our results may shed light on the apparent paradox that persons with low birth weight have an increased risk of T2D as adults, ${ }^{1,2}$ but have lower adult BMI relative to persons with normal birth weight. ${ }^{6-8}$ Neuroendocrine alterations present in persons with low birth weight ${ }^{10-13}$ may explain in part these conflicting observations. Although mechanisms leading from compromised fetal growth to adult diabetes are not completely understood, growing evidence shows that alterations of the neuroendocrine system play a key role in the development of metabolic disorders (for example, T2D, cardiovascular disease) later in life. ${ }^{48,49}$ We propose that, because of the neuroendocrine alterations, normal CNS mechanisms of body weight regulation may be dysfunctional and blind to the presence of common variation in CNS genes.

The present study has several strengths including its large size, and ability to control for important confounding variables. It also has some limitations. First, information on birth weight was self-reported many years after the fact, raising the possibility of non-differential exposure misclassification. However, we found high correlation between selfreported birth weight and birth registry data in our validation study. ${ }^{9}$ Second, although TMEM18, PCSK1 and FTO are highly expressed in the CNS, they are also expressed in other tissues. Therefore, we cannot rule out the possibility that the observed interactions are also mediated by gene activity in other tissues (for example, adipose and pancreas). Third, the SNPs that were assessed in the present study were selected because of their association with BMI in African ancestry subjects. It remains to be determined whether the same interactions would be observed in other populations such as European- or Asian-ancestry individuals. Finally, we did not have information about maternal characteristics during pregnancy (for example, maternal gestational diabetes and maternal malnutrition) that could affect both birth weight and adult body weight in the offspring and potentially confound our results. However, if gestational diabetes and maternal malnutrition affects adult body weight of the offspring mostly through birth weight, it is unlikely that these unmeasured maternal variables would had a major impact in our results.

In summary, our results show that birth weight modifies the association between BMI-associated gene variants and body weight. Specifically, the association between genetic polymorphisms and body weight was weaker or in the opposite direction in subjects having lower birth weights. The SNPs found interacting with birth weight are nearby genes highly expressed in the CNS, suggesting that normal CNS mechanisms of body weight regulation are altered in persons with low birth weight.

\section{CONFLICT OF INTEREST}

The authors declare no conflict of interest.

\section{ACKNOWLEDGEMENTS}

We thank the BWHS participants for their continuing participation in this research effort. This work was supported by grants R01MD007015 from the National Institute on Minority Health and Health Disparities, R01CA058420 and UM1CA164974 from the National Cancer Institute, and 11SDG7390014 from the American Heart Association. The content is solely the responsibility of the authors and does not necessarily represent the official views of the National Institute on Minority Health and Health Disparities, the National Cancer Institute, the National Institutes of Health, or the American Heart Association.

1 Harder, T., Rodekamp, E., Schellong, K., Dudenhausen, J. W. \& Plagemann, A. Birth weight and subsequent risk of type 2 diabetes: a meta-analysis. Am. J. Epidemiol. 165, 849-857 (2007).

2 Whincup, P. H., Kaye, S. J., Owen, C. G., Huxley, R., Cook, D. G., Anazawa, S. et al. Birth weight and risk of type 2 diabetes: a systematic review. JAMA 300 , 2886-2897 (2008).

3 Dulloo, A. G., Jacquet, J., Seydoux, J. \& Montani, J. P. The thrifty 'catch-up fat' phenotype: its impact on insulin sensitivity during growth trajectories to obesity and metabolic syndrome. Int. J. Obes. (Lond.) 30 (Suppl 4), S23-S35 (2006).

4 Dulloo, A. G. Regulation of fat storage via suppressed thermogenesis: a thrifty phenotype that predisposes individuals with catch-up growth to insulin resistance and obesity. Horm. Res. 65 (Suppl 3), 90-97 (2006).

5 Stocker, C. J., Arch, J. R. \& Cawthorne, M. A. Fetal origins of insulin resistance and obesity. Proc. Nutr. Soc. 64, 143-151 (2005).

6 Yu, Z. B., Han, S. P., Zhu, G. Z., Zhu, C., Wang, X. J., Cao, X. G. et al. Birth weight and subsequent risk of obesity: a systematic review and meta-analysis. Obes. Rev. 12, 525-542 (2011).

7 Zhao, Y., Wang, S. F., Mu, M. \& Sheng, J. Birth weight and overweight/obesity in adults: a meta-analysis. Eur. J. Pediatr. 171, 1737-1746 (2012).

8 Schellong, K., Schulz, S., Harder, T. \& Plagemann, A. Birth weight and long-term overweight risk: systematic review and a meta-analysis including 643,902 persons from 66 studies and 26 countries globally. PLOS ONE 7, e47776 (2012).

9 Ruiz-Narvaez, E. A., Palmer, J. R., Gerlovin, H., Wise, L. A., Vimalananda, V. G., Rosenzweig, J. L. et al. Birth weight and risk of type 2 Diabetes in the black women's health study: does adult bmi play a mediating role? Diabetes Care 37, 2572-2578 (2014).

10 Phillips, D. I., Barker, D. J., Fall, C. H., Seckl, J. R., Whorwood, C. B., Wood, P. J. et al. Elevated plasma cortisol concentrations: a link between low birth weight and the insulin resistance syndrome? J. Clin. Endocrinol. Metab. 83, 757-760 (1998).

11 Phillips, D. I., Walker, B. R., Reynolds, R. M., Flanagan, D. E., Wood, P. J., Osmond, C. et al. Low birth weight predicts elevated plasma cortisol concentrations in adults from 3 populations. Hypertension 35, 1301-1306 (2000).

12 van Montfoort, N., Finken, M. J., le Cessie, S., Dekker, F. W. \& Wit, J. M. Could cortiso explain the association between birth weight and cardiovascular disease in later life? A meta-analysis. Eur. J. Endocrinol. 153, 811-817 (2005).

13 Reynolds, R. M., Walker, B. R., Syddall, H. E., Andrew, R., Wood, P. J. \& Phillips, D. I. Is there a gender difference in the associations of birthweight and adult hypothalamicpituitary-adrenal axis activity? Eur. J. Endocrinol. 152, 249-253 (2005).

14 Desai, M., Guang, H., Ferelli, M., Kallichanda, N. \& Lane, R. H. Programmed upregulation of adipogenic transcription factors in intrauterine growth-restricted offspring. Reprod. Sci. 15, 785-796 (2008).

15 Joss-Moore, L. A., Wang, Y., Campbell, M. S., Moore, B., Yu, X., Callaway, C. W. et al. Uteroplacental insufficiency increases visceral adiposity and visceral adipose PPARgamma2 expression in male rat offspring prior to the onset of obesity. Early Hum. Dev. 86, 179-185 (2010). 
$16 \mathrm{Li}$, C., Johnson, M. S. \& Goran, M. I. Effects of low birth weight on insulin resistance syndrome in caucasian and African-American children. Diabetes Care 24, 2035-2042 (2001).

17 Hill, D. J. Nutritional programming of pancreatic beta-cell plasticity. World J. Diabetes 2, 119-126 (2011).

18 Garofano, A., Czernichow, P. \& Breant, B. Effect of ageing on beta-cell mass and function in rats malnourished during the perinatal period. Diabetologia $\mathbf{4 2}$, 711-718 (1999).

19 Tarry-Adkins, J. L., Chen, J. H., Jones, R. H., Smith, N. H. \& Ozanne, S. E. Poor maternal nutrition leads to alterations in oxidative stress, antioxidant defense capacity, and markers of fibrosis in rat islets: potential underlying mechanisms for development of the diabetic phenotype in later life. FASEB J. 24, 2762-2771 (2010).

20 Thorleifsson, G., Walters, G. B., Gudbjartsson, D. F., Steinthorsdottir, V., Sulem, P. Helgadottir, A. et al. Genome-wide association yields new sequence variants at seven loci that associate with measures of obesity. Nat. Genet. 41, 18-24 (2009).

21 Monda, K. L., Chen, G. K., Taylor, K. C., Palmer, C., Edwards, T. L., Lange, L. A. et al. A meta-analysis identifies new loci associated with body mass index in individuals of African ancestry. Nat. Genet. 45, 690-696 (2013).

22 Scuteri, A., Sanna, S., Chen, W. M., Uda, M., Albai, G., Strait, J. et al. Genome-wide association scan shows genetic variants in the FTO gene are associated with obesityrelated traits. PLoS Genet. 3, e115 (2007).

23 Speliotes, E. K., Willer, C. J., Berndt, S. I., Monda, K. L., Thorleifsson, G., Jackson, A U. et al. Association analyses of 249,796 individuals reveal 18 new loci associated with body mass index. Nat. Genet. 42, 937-948 (2010).

24 Willer, C. J., Speliotes, E. K., Loos, R. J., Li, S., Lindgren, C. M., Heid, I. M. et al. Six new loci associated with body mass index highlight a neuronal influence on body weight regulation. Nat. Genet. 41, 25-34 (2009).

25 Locke, A. E., Kahali, B., Berndt, S. I., Justice, A. E., Pers, T. H., Day, F. R. et al. Genetic studies of body mass index yield new insights for obesity biology. Nature $\mathbf{5 1 8}$, 197-206 (2015)

26 Rosenberg, L., Adams-Campbell, L. \& Palmer, J. R. The Black Women's Health Study: a follow-up study for causes and preventions of illness. J. Am. Med. Womens Assoc. 50, 56-58 (1995).

27 Cozier, Y. C., Palmer, J. R. \& Rosenberg, L. Comparison of methods for collection of DNA samples by mail in the Black Women's Health Study. Ann. Epidemiol. 14, 117-122 (2004).

28 Wise, L. A., Palmer, J. R., Spiegelman, D., Harlow, B. L., Stewart, E. A., Adams-Campbell, L. L. et al. Influence of body size and body fat distribution on risk of uterine leiomyomata in US black women. Epidemiology 16, 346-354 (2005).

29 Block, G., Hartman, A. M. \& Naughton, D. A reduced dietary questionnaire: development and validation. Epidemiology 1, 58-64 (1990).

30 Diet*Calc Analysis Program, Version 1.4.1. National Cancer Institute, Applied Research Program, Bethesda, MD (2005).

31 Hoggart, C. J., Parra, E. J., Shriver, M. D., Bonilla, C., Kittles, R. A., Clayton, D. G. et al. Control of confounding of genetic associations in stratified populations. Am. J. Hum. Genet. 72, 1492-1504 (2003).

32 McKeigue, P. M., Carpenter, J. R., Parra, E. J. \& Shriver, M. D. Estimation of admixture and detection of linkage in admixed populations by a Bayesian approach: application to African-American populations. Ann. Hum. Genet. 64, 171-186 (2000).

33 Almen, M. S., Jacobsson, J. A., Shaik, J. H., Olszewski, P. K., Cedernaes, J., Alsio, J. et al. The obesity gene, TMEM18, is of ancient origin, found in majority of neuronal cells in all major brain regions and associated with obesity in severely obese children. BMC Med. Genet. 11, 58 (2010).

34 Bernhard, F., Landgraf, K., Kloting, N., Berthold, A., Buttner, P., Friebe, D. et al. Functional relevance of genes implicated by obesity genome-wide association study signals for human adipocyte biology. Diabetologia 56, 311-322 (2013).

35 Gutierrez-Aguilar, R., Kim, D. H., Woods, S. C. \& Seeley, R. J. Expression of new loci associated with obesity in diet-induced obese rats: from genetics to physiology. Obesity (Silver Spring) 20, 306-312 (2012).

36 Yoganathan, P., Karunakaran, S., Ho, M. M. \& Clee, S. M. Nutritional regulation of genome-wide association obesity genes in a tissue-dependent manner. Nutr. Metab. (Lond.) 9, 65 (2012).

37 Goodge, K. A. \& Hutton, J. C. Translational regulation of proinsulin biosynthesis and proinsulin conversion in the pancreatic beta-cell. Semin. Cell Dev. Biol. 11, 235-242 (2000).

38 Seidah, N. G., Benjannet, S., Hamelin, J., Mamarbachi, A. M., Basak, A., Marcinkiewicz, J. et al. The subtilisin/kexin family of precursor convertases. Emphasis on PC1, PC2/7B2, POMC and the novel enzyme SKI-1. Ann. N. Y. Acad. Sci. 885, 57-74 (1999).

39 Jansen, E., Ayoubi, T. A., Meulemans, S. M. \& Van de Ven, W. J. Neuroendocrinespecific expression of the human prohormone convertase 1 gene. Hormonal regulation of transcription through distinct cAMP response elements. J Biol. Chem. 270, 15391-15397 (1995).

40 Jackson, R. S., Creemers, J. W., Farooqi, I. S., Raffin-Sanson, M. L., Varro, A., Dockray, G. J. et al. Small-intestinal dysfunction accompanies the complex endocrinopathy of human proprotein convertase 1 deficiency. J. Clin. Invest. 112, 1550-1560 (2003).

41 Martin, M. G., Lindberg, I., Solorzano-Vargas, R. S., Wang, J., Avitzur, Y., Bandsma, R. et al. Congenital proprotein convertase $1 / 3$ deficiency causes malabsorptive diarrhea and other endocrinopathies in a pediatric cohort. Gastroenterology 145, 138-148 (2013).

42 Frayling, T. M., Timpson, N. J., Weedon, M. N., Zeggini, E., Freathy, R. M., Lindgren, C. M. et al. A common variant in the FTO gene is associated with body mass index and predisposes to childhood and adult obesity. Science 316, 889-894 (2007).

43 Gerken, T., Girard, C. A., Tung, Y. C., Webby, C. J., Saudek, V., Hewitson, K. S. et al. The obesity-associated FTO gene encodes a 2-oxoglutarate-dependent nucleic acid demethylase. Science 318, 1469-1472 (2007).

44 Jia, G., Fu, Y., Zhao, X., Dai, Q., Zheng, G., Yang, Y. et al. N6-methyladenosine in nuclear RNA is a major substrate of the obesity-associated FTO. Nat. Chem. Biol. 7, 885-887 (2011).

45 Cecil, J. E., Tavendale, R., Watt, P., Hetherington, M. M. \& Palmer, C. N. An obesityassociated FTO gene variant and increased energy intake in children. N. Engl. J. Med. 359, 2558-2566 (2008).

46 Park, S. L., Cheng, I., Pendergrass, S. A., Kucharska-Newton, A. M., Lim, U., Ambite, J. L. et al. Association of the FTO obesity risk variant rs8050136 with percentage of energy intake from fat in multiple racial/ethnic populations: the PAGE study. Am. J. Epidemiol. 178, 780-790 (2013).

47 Wardle, J., Llewellyn, C., Sanderson, S. \& Plomin, R. The FTO gene and measured food intake in children. Int. J. Obes. (Lond.) 33, 42-45 (2009).

48 Fisher, R. E., Steele, M. \& Karrow, N. A. Fetal programming of the neuroendocrineimmune system and metabolic disease. J. Pregnancy 2012, 792934 (2012).

49 Phillips, D. I. \& Matthews, S. G. Is perinatal neuroendocrine programming involved in the developmental origins of metabolic disorders? World J. Diabetes 2, 211-216 (2011). 